\title{
Notes on the First Stanza of Fragment 17
}

\author{
Joel Lidov
}

The opening lines of fr. 17 present a wealth of choices, but nonetheless remain exceptionally difficult to supplement satisfactorily. The following comments are meant to clarify the problems and possibilities. I add an exploratory suggestion for the first two lines.

(1.) In line 1, the sequence . . o o $\alpha[$ could be divided . . o o $\sigma \alpha[$ (3rd pers. opt. singular of a thematic verb), . . . oเ $\alpha$ [- (second declension accusative plural or second person optative) or . . o o $\sigma^{\prime} \alpha[$ (dative masculine/feminine or-with or without elision-nominative or vocative feminine participle). Meter and spacing make it likely that the preceding traces represent the sequence consonant, vowel, consonant, rather than a sequence containing an open vowel. The traces suggest that rho is mostly likely for the first consonant, epsilon for the vowel (that is, the other vowels appear to be excluded), and a triangular letter such as lambda, kappa or chi (less likely delta) for the second consonant. (A reading of $F \varepsilon$ is physically possible, but I do not see how it could be fit into a sentence).

(2.) The final omega of line 1 could be, as a verb, the first-person singular indicative, present or future, or subjunctive, aorist or present, or a third-person singular imperative; as a noun it could be a feminine nominative (typically a proper noun, of a type like $\Psi \alpha \dot{\alpha} \varphi \omega)$, or a second-declension genitive.

(3.) The initial $\pi \lambda \alpha \dot{\sigma}$ เov would most likely be construed with a genitive, but it could be used alone. With a genitive at line end, it might be possible to

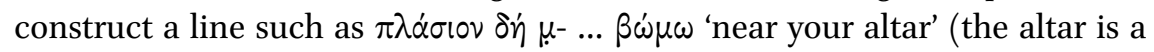
feature of the Messon sanctuary mentioned in Alc. fr. 129.3; Prof. Fish assures me that this would fit the spacing). ${ }^{1}$

1 Ferrari (2014) 16 and Neri (2014) 14 suggest that if used absolutely here, $\pi \lambda \dot{\alpha} \sigma$ เov would serve the expected deictic function, locating the performance (there are no other examples of $\pi \lambda \dot{\alpha} \sigma 10 \mathrm{v}$ used this way). I think it is also possible that the precinct is large enough for the performance of the song (perhaps at an altar or before a shrine) and the multiple activities of a festival to be in different, but adjacent, places. I am not persuaded by Neri's or Caciagli's (this volume)

(C) JOEL LIDOV, 2016 | DOI: 10.1163/9789004314832_021

This is an open access chapter distributed under the terms of the Creative Commons Attribution- 
(4.) A dative in the gap is not excluded, if it could be construed with a verb, perhaps a compound verb; the verbs most typically found with $\pi \lambda \dot{\alpha} \sigma 10 \mathrm{v}$ have the meanings 'be', 'stand', 'lie', or 'sit'. A participle with such a meaning here would have to agree with Hera (vocative or as subject of a second person verb

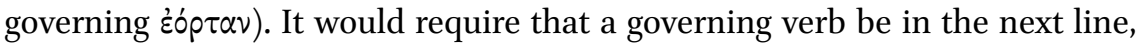
which would be difficult. On the other hand, a dative would be attractive if it suggested a parallel with a dative in lines 3-4.

(5.) Two tendencies peculiar to Book 1 may constrain supplements in line 1: there are few, if any, middle participles outside fr. 2 (as discussed in the main article); and, although there are many references to speech and prayer, there are only a few uses of the specific vocabulary of music or singing (fragments 21.12, $27.5,30.4)$, none of them referring to the performance in progress. These con-

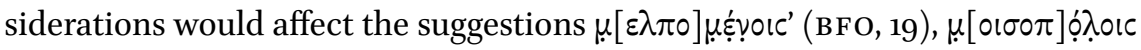
(Ferrari 2014, 15-16), $\alpha$ [ $[\varepsilon i \delta] \omega$ (Lidov in BFO, 19, which is in any case too short).

(6.) In the second line the nominative " $\mathrm{H} \rho \alpha$, is excluded by the meter. If Hera is also the agent in these lines, there must be an optative second person verb in line 1. However, she may be the addressee interested in or responsible for the fulfillment of a first- or third-person wish or statement.

(7.) The final traces of the second line allow only the alternatives cóp $\tau[\alpha]$ or

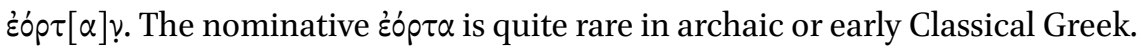
If the word ends in - $\alpha \nu$ - genitive plural (see below) or accusative singular - the preceding $c \alpha$ might be emended to $\sigma \alpha\langle\nu\rangle$ (or $\sigma \alpha\langle\gamma\rangle$, to accommodate assimilation before chi). The most common verbs in Greek for conducting a festival appear to me to be $\pi \circ \varepsilon^{\varepsilon} \omega$ and $\alpha^{\prime} \gamma \omega$ (or $\left.\alpha \nu \alpha \gamma \gamma \omega\right)$. The former occurs twice more in the poem (lines 3 and 11) apparently in regard to performance of the rituals of this festival, even though the instance in line 11 has a neuter plural object; the latter, in a passive construction with the nominative form, is suggested in Burris, Fish, and Obbink (2014) 19 to supplement the end of line 1: $\alpha[\gamma \varepsilon \dot{\varepsilon} \theta \theta]$.

(8.) The word that is the most obvious supplement for the preceding gap,

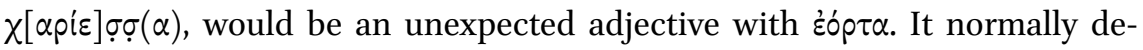
scribes particular things that can be appreciated in a moment of sensation, typically by a person present: the works or accomplishments of men (generally

examples of passages in which a dative could be construed with $\pi \lambda \dot{\alpha} \sigma$ เov that they are better read that way. 
in Homer; see LSJ s.v. and Broger 1996, 33), the sound of a song (Pindar Pythian 5.107) or of a chorus (Alcman fr. 27.3), the sensation of a grove (Sappho fr. 2.2), the beauty of a bride (Sappho fr. 108 and fr. 112.3), the pleasantry of a sympotic companion (Alcaeus fr. 368.1; this instance resembles the later Attic use to designate social charm). It would more likely describe a single event at a festival than the festival itself, which extends over a period of time and encompasses

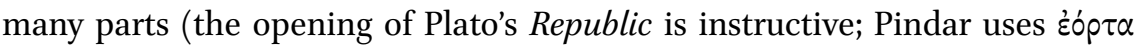
several times for the combination of sacrifice, contests and other activitiesthat is, a 'festival,' not merely 'games'). However, in a hymnic context it can also describe something pleasing to the god, the usual use of a $\chi \alpha p$ - form in a hymn: a temple roof (Iliad 1.139) or a choral performance (Pindar Nemean 3.10-13). Nonetheless, it remains open whether $\chi\left[\alpha \rho^{\prime} \varepsilon\right] \sigma \sigma^{\prime}$ itself is the best word to complete this thought.

(9.) $\chi \alpha$ pi $\varepsilon \sigma \sigma \alpha$ would be even more unexpected as an epithet of Hera (the word is not used of gods, let alone as a free-standing epithet), which is what it

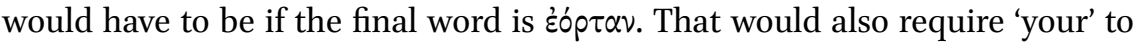
be emended to the accusative. The interleaved word-order-vocative name, accusative possessive adjective, vocative adjective, accusative noun-strikes me as strained (certainly, if cóp $\tau \alpha$ were nominative, no one would read the adjective here to be vocative with the name).

(10.) Any $\chi \alpha \rho$ - word would suggest a mention of a festival in terms of the mutual pleasure of men and gods, a reading that would satisfy the general expectation that the gods accept or are pleased by the mortals' effort or dedication. We find this idea with żóp $\tau \alpha$ and a different word for 'pleasing' in Alcman fr. 56.1-2: ö $x \alpha$

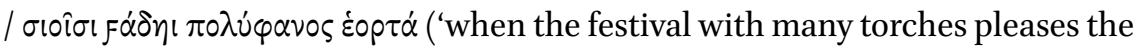

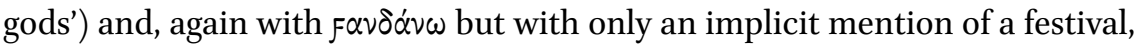
in Homeric Hymn XIV, to the Mother of the Gods, to describe her pleasure in the noises made in celebration. Since some scholars (since Robert 196oa) have argued that Hera is assimilated to Mater in the Messon temenos, this could be particularly relevant here. Metrically, $\mu[\hat{\alpha} \tau \varepsilon] \rho$ (or $M[\hat{\alpha} \tau \varepsilon] \rho)$ would fit in the gap in line 1 , though it is on the short side. If we think in terms of a noisy festival (as I have already suggested for fr. 5), 0 ] $\times \lambda$ os in line 13 makes more sense, and the connection to Alcaeus fr. 130b.18-20, 'the sound of the sacred yearly shout', is strengthened.

(11.) An alternative to $\chi[\alpha p i \varepsilon] c c^{\prime}$ could be $\sigma \dot{\alpha} \chi[\dot{\alpha} p i c$.]c., the noun originally suggested by Fränkel ([1975] 182 n. 31) to represent Hera as subject. It could be independent of 'festival' in the nominative or govern it as a genitive plural. 
$\sigma \dot{\alpha}\langle\nu\rangle \chi[\dot{\alpha} \rho \imath=$ 'for your sake' could also be possible. The letter following $] c$ must be a consonant and is most likely a sigma, but could just possibly be tau or theta, allowing an elided infinitive or an imperative such as oi $\sigma \theta^{\prime}(\alpha)$ or " $" \sigma \theta^{\prime}(\iota)$ with $\chi \alpha \dot{\alpha} p \downarrow v$. A tau is the basis of Ferrari's suggestion ([2014] 15-16):

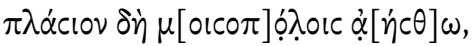

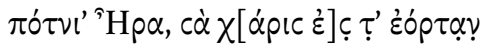

Qui vicino spiri il tuo favore verso i ministri delle Muse, Hera veneranda, e verso la festa

This satisfies many conditions for these lines, but remains problematic. For the noun and the traces in the first line, see above; in addition, it seems somewhat odd to call the chorus 'servants of the Muses' at the very moment that they are attendants of Hera. There is no reason to suppose that the word had already lost its specificity in the parallel cited, Sappho fr. 150.1. As Ferrari's translation shows, the idea of motion here is obscured, rather than avoided. Finally, the postponement of the preposition to so distant a position after its first object would be extreme even in Pindar. With a theta, we could try a genitive plural:

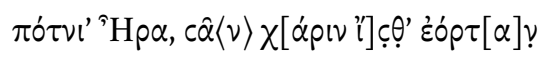

Lady Hera, be grateful for—or: know the gratitude of—your festivals.

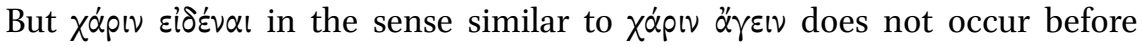
Isocrates and I cannot find a parallel for taking such an expression to be equiv-

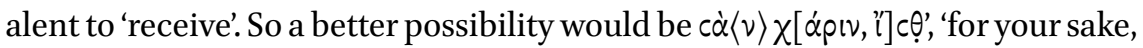
be sure, ...' with 'a festival' as the subject or object of a construction in line 1.

(12.) The problem, then, is to put together supplements for lines 1-2 that would fit the traces, avoid the likely restraints mentioned above, as well as unlikely or awkward constructions, and emphasize or at least be consistent with the performer's or the god's interest in the pleasure the god derives from a festival as prerequisite to the favor the god will show. So I suggest a form of $\tilde{\varepsilon} \kappa \omega \nu$, a word found in archaic epic and lyric, though not in Aeolic, to emphasize the performer's desire to please:

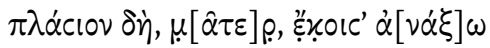

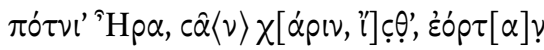


Nearby, mother, I willingly will lead

a festival, be certain, Lady Hera, for your sake.

This combination of supplements employs the normal verbal idiom for festivals, locates the action at the shrine, incorporates the reference to Hera as genethla in Alcaeus fr. 129 (and, obviously, depends on the syncretism with the worship of the Mother figure), shows a structure parallel to Alcaeus fr. 308 ,

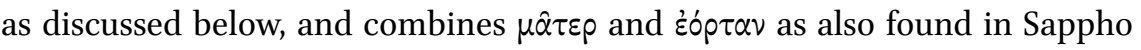
fr. 9. On the other hand, the supplements in the gaps, especially the first, are only marginally long enough and the reading of the verb employs the less wellestablished alpha-form of the prefix (see app. crit. to Sappho fr. 16.15 in this volume, and Voigt's index s.v. ov $v$ ). Because I have emphasized the absence of a declaration of the gender of the singing persona in fr. 5 and the Charaxos poem, I would prefer a word to describe the festival itself as the source of pleasure, perhaps using the structure $-0 / \sigma \alpha[\nu \propto \alpha \xi] \omega .^{2}$ But whatever its shortcomings, this supplement creates a meaning and context that may suggest new avenues for exploring the poem.

(13.) In line 3 it has been assumed, since the discovery of the new fragments,

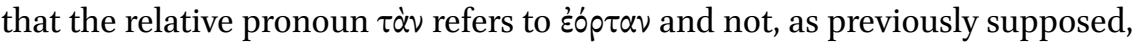
to 'Hera, your' (a possessive adjective as antecedent is normal [Kühner and Gerth (1904) sect. 544(.3) anmerk. 4]). This new reading has the advantage of being a very easy syntactic sequence. We can, however, still take it with Hera and there are reasons to do so (it would be necessary to do so if źóp $\tau \alpha \nu$ is the genitive plural). The verbal adjective ápátav should mean 'prayed for' or 'prayed to' (I am assuming that the Homeric pejorative use, 'prayed against',

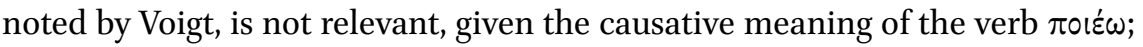
I defended it in Lidov [2004] under the impression that a verb of perception could be supplied). But one prays for what the gods give-objects of desire: goods, a marriage, a safe return-and a festival is not a divine gift. On the contrary, it is a human gift to the god. ${ }^{3}$ The verb cannot be taken to mean

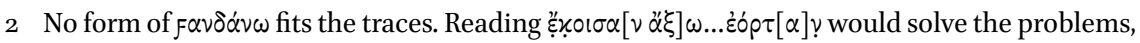
but I have not found any parallel to justify transferring this attribute of participants to the festival itself.

3 S. Caciagli in this volume recognizes the problem, and the advantage of a word describing something pleasing to Hera that I discussed in regard to the first two lines, and suggests that $\alpha \rho \dot{\alpha} \tau \alpha \nu$ here can have the meaning 'attractive, agreeable'; he draws attention to the unmetrical correction épó $\tau \alpha \nu$ in $P S I 123$ (which is irrelevant; we have no idea how the corrector understood the original text) and to the use of the hapax àpntóv in Callim. Hymn 4.205 as 
'vowed'. LSJ s.v. àpáoual I.A.4 is misleading in its sole citation, Iliad 23.144, in which Achilles says that Peleus prayed 'if Achilles return, he will dedicate...' That is, he prayed for Achilles's return, and promised that Achilles would do something if he did return. When Achilles, in the passage cited, turns this into reported speech, $\eta p \eta \dot{\sigma} \sigma \alpha 0$ is the verbum dicendi, the "if clause" becomes a participle, and the apodosis of Peleus' future more vivid condition is expressed

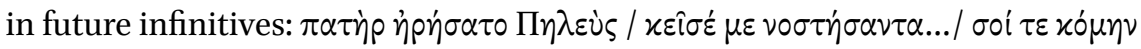

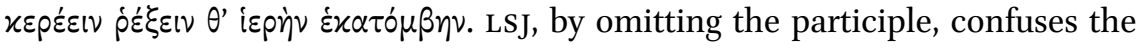
construction. Peleus includes a vow in his prayer for Achilles's return, but that does not give the verb 'pray' the meaning 'vow' 4 It is therefore difficult to make the festival the object. To suppose that the kings prayed that the gods allow them, after leaving Troy, to reach the festival, which they knew about - as if the single word 'festival' by itself could be the equivalent of nostos, something one prays for-requires complicated narrative and semantic inferences for which no clue is given, although of course they are not impossible. But the alternative poses no difficulties. For the construction in which the relative reaches back over a potential nearer antecedent there is a good parallel in Alcaeus fr. 308.1-4:

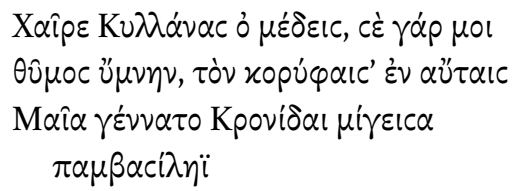

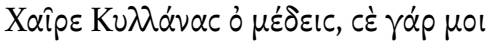

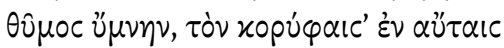

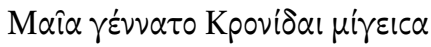

$\pi \alpha \mu \beta \alpha c i \lambda \eta \ddot{~}$

Hail, ruler of Cyllene, for of you it is my will to sing, whom in the very mountains

Maia bore...

Here the "hymnic relative" that begins the second part of the prayer refers back to $\sigma \varepsilon$ rather than to the nearer $\theta \hat{v} \mu о \varsigma$. In Alcaeus' poem $\nu \mu \nu \eta \nu$ refers, as Éóp $\tau \alpha$ apparently does in Sa. fr. 17, to the immediate performance. The paral-

'“gladly.' But the translation there is ad hoc; Leto's receipt from Delos of what she required in her distress-as if in response to prayer or through magical action-does not justify generalizing the sense 'pleasing' to a human gift to a god. (I discussed that passage, and its relation to this line, in more detail in Lidov [2004] 398 n. 18).

4 G. Nagy in this volume defends that meaning in the verb àpóo $\mu \alpha$, despite the absence of any archaic or later example, on topical and comparative grounds: vows are inherently part of prayers, the synchronically synonymous word for prayer eüxoual developed the meaning 'vow', and it also occurs in Latin words of similar meaning. He does not consider the possibility of taking Hera as the antecedent. 


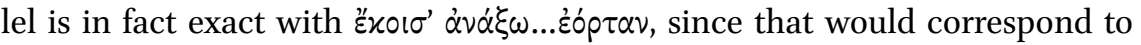

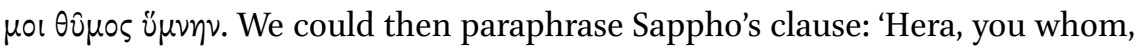
in the middle of their troubles, on behalf of (or at the behest of) the son of Atreus, the kings [anaphoric: 'those (well-known) companions of the son of Atreus'] made - in your (newly established or already existing) festival — the

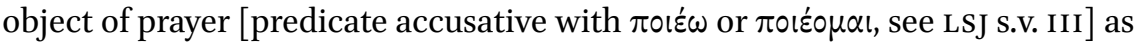
they sought a way to complete their journey safely'. The periphrasis with $\pi \circ \varepsilon \varepsilon \omega$

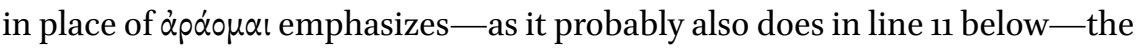
activity of conducting a festival as a means of soliciting the god's good will. The difference in antecedent is a matter of emphasis in the interpretation; a final determination must probably await examples that furnish a better understanding of the semantics of àpatós.

(14.) In line 4 it is highly unlikely that $\tau 0$ is the enclitic pronoun, as West proposes ([2014] 4 with n. 7). ${ }^{5}$ In the modern scholarship Wackernagel's law has been refined to show that enclitics are placed not as the second word, but after the first constituent of their (phonological) clause. (See Dover [1960] 12-24; Taylor [1990] 64-65; Dik [1995] 31-37; Matić [2003]; Dik [2007] 14-41; Bertrand [2008] 239-249. For further bibliography, including references to the fundamental work of Wackernagel and Fränkel on which these scholars build, see Dik [2007] and Bertrand). The definition of 'constituent' gives the composer many options: an initial conjunction may or may not be included, certain adverbs or a string of adverbs may be optionally appositive, and a tightly bound adjective + noun may constitute a single constituent (these all figure in West's examples of enclitics 'placed later than expected'). But in fr. 17.4 three separate lexical words, not in agreement, could not be other than three constituents. In later prose an enclitic pronoun has, as an alternative, a position after the verbas would be the case here-rather than after the first constituent (properly defined) of its clause, but that position is very rare in Homer (if it happens at all; Bertrand [2008] 243); despite some variation in explanation among the

5 An accent mark in the new papyrus raises the possibility (pursued by G. Nagy, in this volume) that a hitherto unrecognized form of the emphatic second person pronoun, toí, occurs here. Neither of the other two papyri with these letters show that their readers found a difficulty with the form; the grammatical tradition (as represented by Apollonius Dyscolus) explicitly says that Attic, Ionic, and Aeolic use ool for the emphatic form and that $\tau 0$ is unaccented (quoted in Voigt, fr. 40 TEST); and the form is not found accented in the texts of Homer or elsewhere in Sappho or Alcaeus. Accepting it here would be to call all of these indicators into question. In any event, the interpretive advantage of doing so, the emphasis on Hera, is achieved more easily by taking her as the antecedent to $\tau \dot{\alpha} \nu$. 
methods derived from various disciplines, the consensus is consistent in this definition. Sappho seems to stay unambiguously within the earlier, Homeric rules. I easily find more than two dozen clear examples of the postpositive pronoun in second position in all the fragments, but none of the few possible examples of the contrary are certain (some are supplied by editors; some are potentially the emphatic pronoun, following an elided epsilon; some are open to multiple interpretations; some, all of these.) A consequence of this is that only the middle $\pi \circ \eta^{\prime} \sigma \alpha v-/ \tau^{\prime}$ is possible, since $\tau o$ is not found as the demonstrative or article. ${ }^{6}$ In oi $\beta \alpha \sigma_{i} \lambda \eta \varepsilon s$ the article would be anaphoric, referring back to well-known kings associated with the son of Atreus. Note, in addition, that the new confirmation of the adjective phrase $F \hat{\varphi} \theta \dot{\mu} \mu \omega \iota$ $\chi \varepsilon$ (instead of the enclitic pronouon fol) in fr. 5.3 guarantees that the enclitic $x \varepsilon$ is in a normal position. (The rule also affects the interpretation of fr. $96.15^{-17}$, where the position of $\pi$ ol indicates that i $\mu \varepsilon \dot{\varepsilon} \rho \iota \mathrm{l}$ must belong with the preceding participle, 'remembering Atthis with desire', and that a new phrase begins with $\lambda \varepsilon \dot{\pi} \tau \alpha \nu)$.

(15.) There is a difficulty in line 11, where the only possible letters before $\pi$ ón$\mu \varepsilon v$ are $\beta \bar{l}$, or $\rho \bar{l}$, or most likely $\rho \bar{\alpha}$, and this syllable must be preceded by an open short syllable. For the first two, the less likely readings, I have found no possible supplement. For the third, West's suggested $\pi \dot{\varepsilon} \rho \alpha$ ([2014] 4) is, as far as I can find, the only word available as part of the syntax (a first declension nominative is excluded by the plural verb). In the context, as he says, $\pi \dot{\varepsilon} p \alpha$ đón$\mu \varepsilon \nu$ would have to mean 'continue to do'. But the word, not found elsewhere in early Greek, is always accompanied by the idea of a limit: 'beyond, exceeding, excessively', and is most common with a negative: 'no further' (see citations in $L S J$ ). Simon Burris's suggestion (see Obbink's apparatus criticus in ch. 1 of this volume), that the word could be the feminine vocative of a three-ending

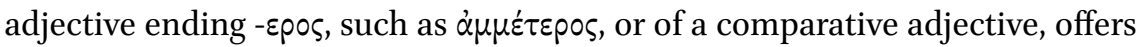
more opportunities (a vocative noun would have a short alpha). I do not know if the same god can be addressed at the middle as well as at the beginning and end of one prayer of this length, but the addressee could also be one who assists in the performance, such as a Muse or one of the participants, although the fragments of Book One offer no other examples. An address to Hera to

6 The Homeric demonstrative could have the tau: such an epicism would be consistent with the less-unusual missing augment in the previous line but inconsistent with the short first alpha of $\alpha$ pá $\tau \alpha \nu$. The emphasis of a deictic demonstrative in this position strikes me as awkward, but it makes little difference to the overall sense. 
give direct assistance (rather than through a helper) would be unusual both in respect to the form I have discussed and to the usual representations of Hera, but cannot be ruled out.

(16.) In the final adonean Hera's name is the most likely supplement for the first word of the readable letters, - ] $\rho(') \alpha \pi i x \varepsilon[$ (scil. $\alpha \pi i x \varepsilon \sigma \theta \alpha \mathrm{l})$. A run-over word ending - $\eta \rho^{\prime}$ would have to have an open vowel in the syllable ending the preceding line, and I have found no likely candidate. The epsilon in the fourth syllable of line 20, visible only in the P.Oxy. fragments, precludes an imperative (a long syllable is required), so the form must be the infinitive. 